\title{
EUROPEAN COVID -19 PANDEMIC DATA AND SOCIAL INCLUSION POLICY IN THE EUROPEAN UNION: DRIVERS-DRIVEN TREND ANALYSIS
}

\author{
Jari Kaivo-oja ${ }^{1,2}$, Samuli Aho ${ }^{3}$, Theresa Lauraéus ${ }^{1,2}$ \\ ${ }^{1}$ Kazimiero Simonavičiaus University, Vilnius, Lithuania, \\ ${ }^{2}$ Finland Futures Research Centre, Turku School of Economics, University of Turku, Turku, Finland \\ jari.kaivo-oja@utu.fi,theresa.lauraeus@aalto.fi \\ ${ }^{3}$ University of Vaasa, Vaasa, Finland samuliaho563@gmail.com
}

\begin{abstract}
Research purpose. The study is focused on the Covid-19 pandemic crisis in the European Union. This study investigates the current driving trends and trade-offs of the Covid-19 pandemic phenomenon and social inclusion trends in the European countries.

Design / Methodology / Approach. The methodology is based on conventional statistical index theory and statistics. The study investigates cases, deaths, and key Covid-19 statistics. The research design combines key social inclusion statistics of the Eurostat and the official Covid-19 statistics of the European Centre for Disease Prevention and Control. Covid-19 data is updated to 1.3.2021. Social inclusion variables are selected from the Eurostat database. Social inclusion variables cover poverty, material deprivation, income distribution, income, quality of life, employment, and education matters. Scattering matrices on the relationships among the key variables under review are reported.
\end{abstract}

Findings. The study reports basic trends of Covid-19 cases, deaths, deaths/cases and calculates these Covid-19 trends in 29 European countries. This study reports trade-off analyses of key social inclusion trends of the European Union countries. Key indicators are linked to economic income, income distribution, poverty, gender issues, and housing statistics. The 19 key indicators of social inclusion are analysed and reported with Covid-19 data. Statistical correlation analysis tables ( $2 a$ and $2 b$ ) are calculated with key European social inclusion indicators. The study reveals some relevant aspects of the social inclusion policy of the European Union about the ongoing Covid-19 crisis and exit strategies.

Originality / Value / Practical implications. This conference paper demonstrates novel and exciting possibilities of integrated data pooling (The Eurostat and the European Centre for Disease Prevention and Control). Original results of key trend drivers are provided by the authors. Value-adding and interesting results are delivered for European governments and the business community. Results and findings of the study can be used in the planning of economic recovery and Covid-19 exit policies in the member states of the European Union.

Keywords: Covid-19; Pandemic data analytics; Social inclusion; European Union; Trend analysis; Trend drivers; Trade-offs analysis.

JEL codes: H10, I32, I38, J10, N14.

\section{Introduction}

The importance of social inclusion variables has been recognised in numerous international studies, also during the Covid-19 crisis. During and after the corona crisis, attention should be paid to the content of social inclusion policies. This research can help decision-makers in this regard. Previous studies have compared the corona crisis to the Great Recession of the 1930s (Arbolino \& Di Caro 2021). It is good to understand that social inclusion policy is linked to Industry 4.0 developments (Mendoza-del Villar et al. 2020). The policy of social inclusion in the European Union will have to be reassessed in the wake 
of the interest rate crisis (see, e.g. Schoukens et al. 2015). The post-coronary crisis strategy for the social inclusion policy in the European Union must be carefully reconsidered.

This article is organised in the following way. First, we present trade-of trends between the Gini coefficient and the number of Covid-19-related deaths in Europe. It shows that in Europe, the trade-off relationship is not very clear between these key variables. In sections $1-5$, we investigate various tradeoffs between social inclusion variables and the number of Covid-19 deaths concerning the population in European countries. Our approach is explorative, and we aim to study social inclusion variables in thematic groups: poverty variables, material deprivation variables, income distribution variables, income and quality of life variables, employment variables, and finally, education variables. Our data sample covers 29 European countries. In section 4, we present a summary of trade-off analyses (Table 1) and a correlation analysis of key variables. In section 6 , we conclude. Thus, section 6 includes conclusions and reflections.

\section{Literature Review}

The importance of social inclusion variables has been recognised in numerous international studies, also during the Covid-19 crisis. Several studies have focused on the position of the elderly population during the coronary crisis. There is a lot of literature on the ageing population in a pandemic situations available (Cacioppo \& Cacioppo 2014, Courtin \& Knapp 2017, Cudjoe et al. 2020, Hayashi et al. 2020, Xie et al. 2020). These studies focus on assessing the COVID-19 crisis and the role of the social inclusion variable in the European Union. Cutiérrez and Ahamed have presented an extensive survey of COVID-19 response need to broaden financial inclusion to curb the rise in poverty (Cutiérrez \& Ahamed 2021). COVID-19 crisis is closely linked to three pillars of sustainability. (Ranjbari et al. 2021), where social inclusion is linked to the pillar of social development. This article in the World Development journal discusses the COVID-19 crisis from a global perspective. In this particular article, we focus on the European Union.

\section{Research methodology}

Our methodological approach is quite similar to a study in Social Science \& Medicine (see Elgar et al. 2020; see also Nummenmaa et al. 2017). In this study, we pay attention to various variables of social inclusion, and in particular to those variables that Eurostat has assessed as key variables. Our basic hypothesis is that the lack of social inclusion exposes EU citizens to corona virus-related deaths. We thus assess the importance of social inclusion in the context of the corona crisis. We aim to assess this research problem by combining social inclusion variables with statistics on Covid-19 mortality and deaths in Europe. Our trend research is focused on the European continent and the European Union. The basic design of the study is shown in Figure 1. We aim to present to the specification the dimensions of social inclusion related to the corona pandemic using different measurable variables. We have selected 19 key variables of social inclusion for this European driver-driven trend study.

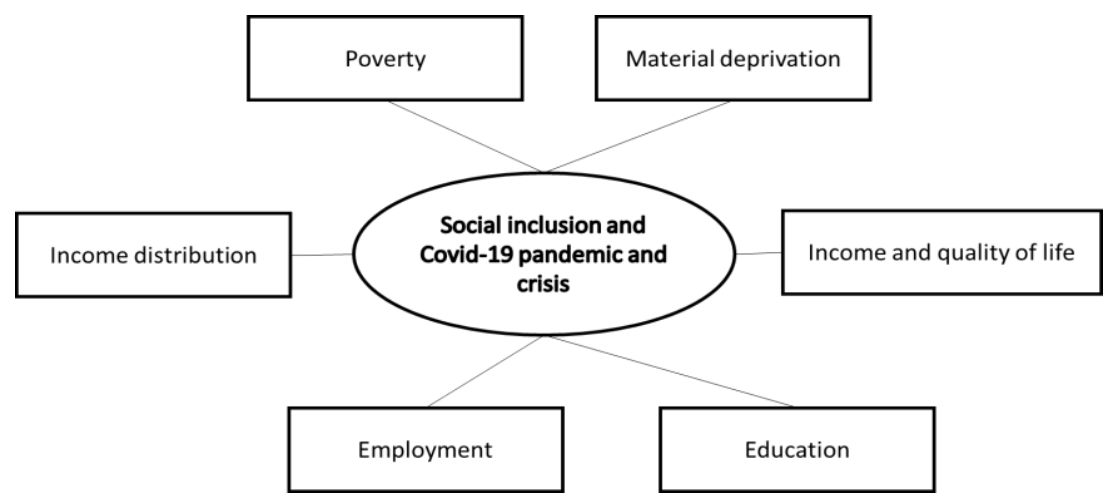

Fig. 1. Social inclusion and COVID-19 pandemic and crisis. 
The survey data have been collected from Eurostat's statistical sources (Eurostat 2021) on social inclusion and official statistics from the European Centre for Disease Prevention (ECDP 2021). In this study, we have also make a correlation analysis. The Pearson correlation coefficients (PCC, pronounced /'prorsən/) are reported following basic guidelines of statistical correlation analysis, also referred to as Pearson's $r$, the Pearson product-moment correlation coefficient (PPMCC), or the bivariate correlation. It is a measure of linear correlation between two sets of data (see Nummenmaa et al., 2017, chapter 8).

\section{Results}

Section 1. Gini-Coefficient and Covid-19 Deaths/Population in Europe

Trade off analysis of GINI and CAS/POP/DEATHS/POP

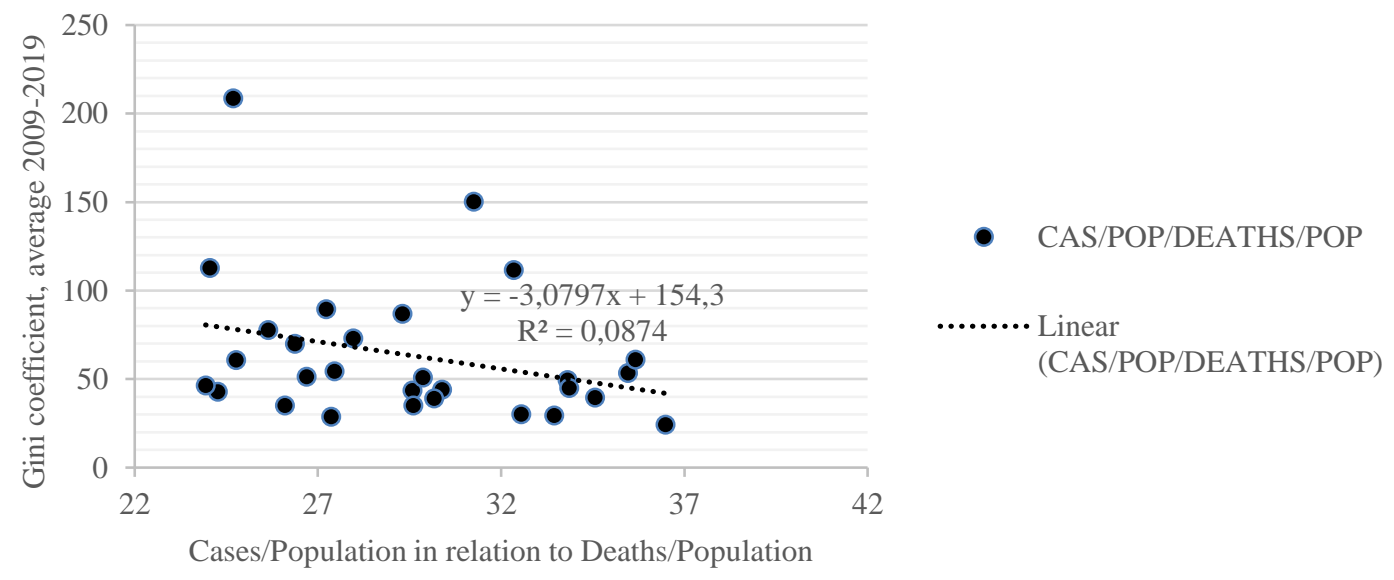

Fig. 2. Trade-off Gini coefficient, average, 2009-2019 and Cases/Population to Deaths/Population (Source: Eurostat 2021 and ECDP 2021)

First, we report our trade-off analysis of Gini-coefficient and Covid-19 deaths/population in the European Union (Fig. 2). As we can observe, there is not a very clear linear relationship between these two variables: Covid-19 deaths/population and Gini coefficient. It is advisable to keep in mind when we analyse other relationships between a variable Covid-19 Cases/Population to Deaths/Population and social inclusion.

\section{Section 2: Social inclusion and deaths per population during Covid-19 crisis: Employment}

In this section, we report various trade-offs between social inclusion variables and deaths in 29 European countries. We report conventional scatter diagrams showing two key variables (see Nummenmaa et al., 2017). The aim of the study is to provide information on how social inclusion variables are potentially linked to a variable Covid-19 Cases/Population to variable to Deaths/Population.

This kind of explorative analysis can help us to create a "big picture" of complex phenomena. We are not aiming to present hypotheses of complex causal relationships. We can present some good work hypotheses and test them later with statistical regression models. Our analyses in this article can help to build later more sophisticated linear or non-linear regression models. 
Trade off analysis of INEQ-INCOME and CAS/POP/DEATHS/POP

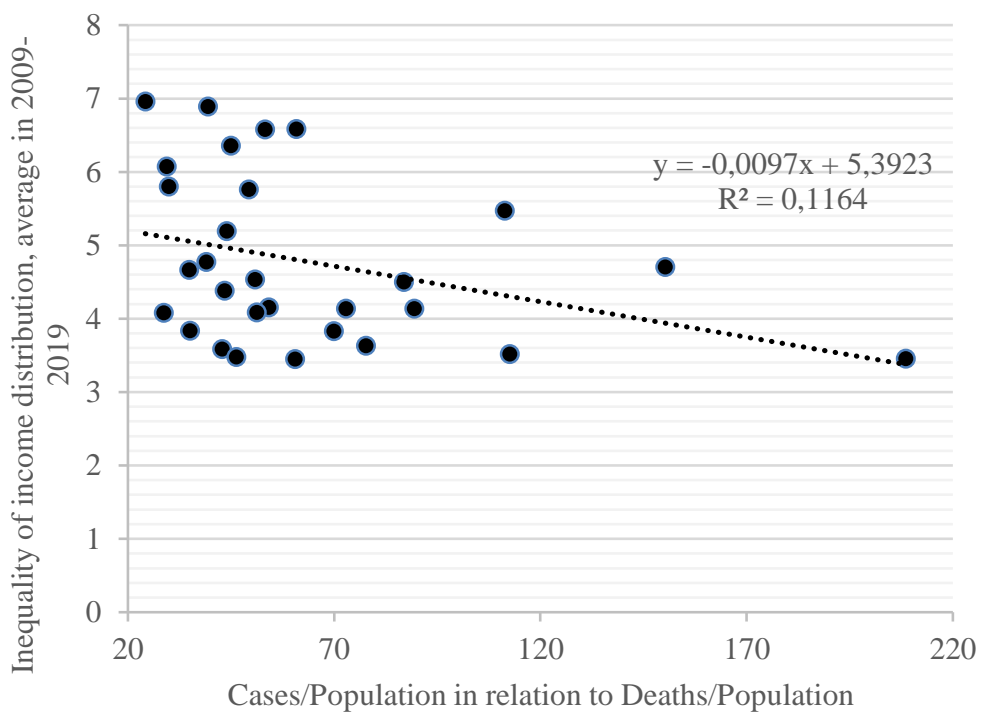

- Inequality of income distribution, average in 20092019 INEQ-INCOME

Linear (Inequality of income distribution, average in 20092019 INEQ-INCOME)

Fig. 3. Trade-off Inequality of income distribution, average in 2009-2019 and Cases/Population to Deaths/Population (Source: Eurostat 2021 and ECDP 2021)

We can observe a negative slope between these two variables (Fig. 3). In European countries, the high average employment rate has been able to lower variable Cases/Population to Deaths/Population. Expressed the other way around, the unemployment rate seems to lead to higher Covid cases and death rates to the population as social inclusion variable. This is, of course, a relevant and very interesting finding. In Fig. 4, we report a trade-off analysis between the average employment rate of older workers, age group 55-64, in 2005-2019, and a variable Covid-19 Cases/Population to Deaths/Population.

Trade off analysis of CAS/POP/DEATHS/POP and EMPOLDWORKERS

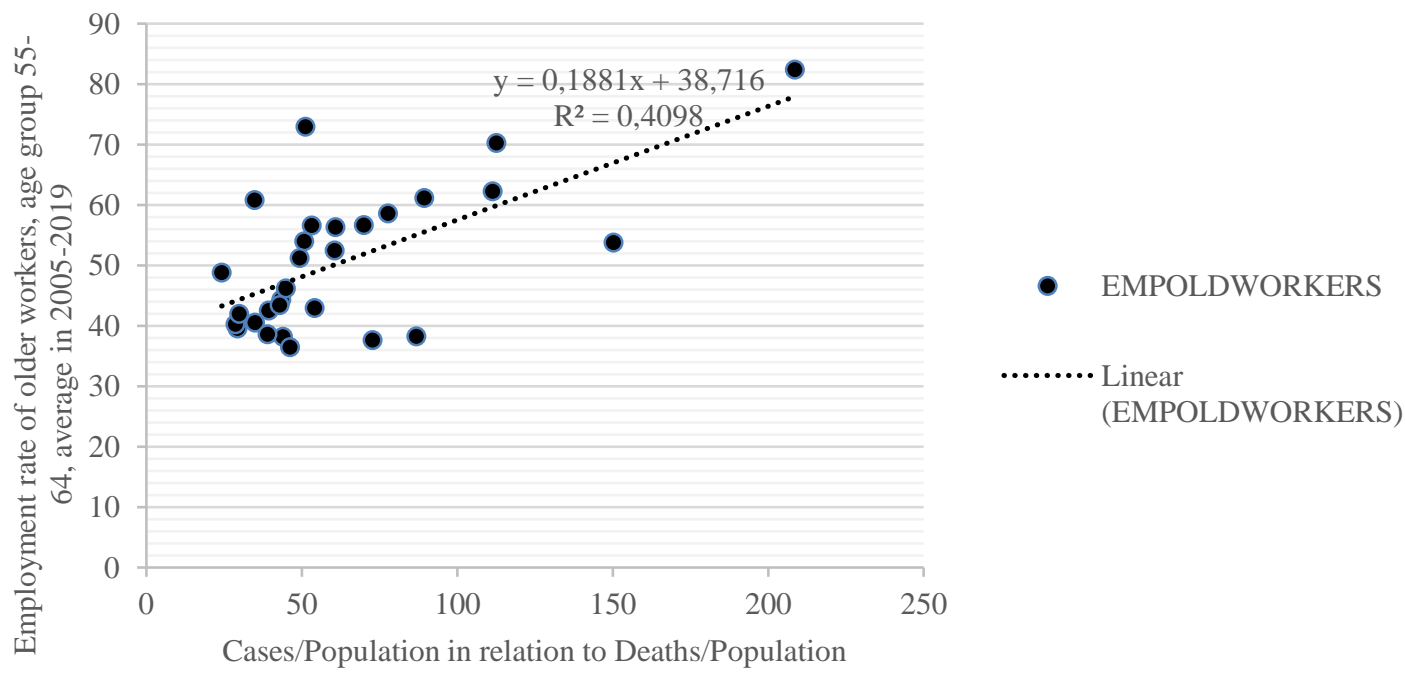

Fig. 4. The trade-off Employment rate of older workers, age group 55-64, average, in 2005-2019 and Cases/Population to Deaths/Population (Source: Eurostat 2021 and ECDP 2021) 
We can observe a positive slope between these two variables (Fig. 4). In European countries, the high employment rate of older workers has been able to lower the number of Covid-19 cases and death rates to the population. Expressed the other way around, the unemployment rate of older workers in the age group 55-64 seems to lead to a higher number of cases and death rates as a social inclusion variable. This is a important and remarkable finding for the decision-makers of the European Union. The special attention paid to older people in European countries has been entirely appropriate.

In Fig. 5, we report a trade-off analysis between the average youth unemployment rate by sex, in 20052019, and a variable Covid-19 Cases/Population to Deaths/Population.

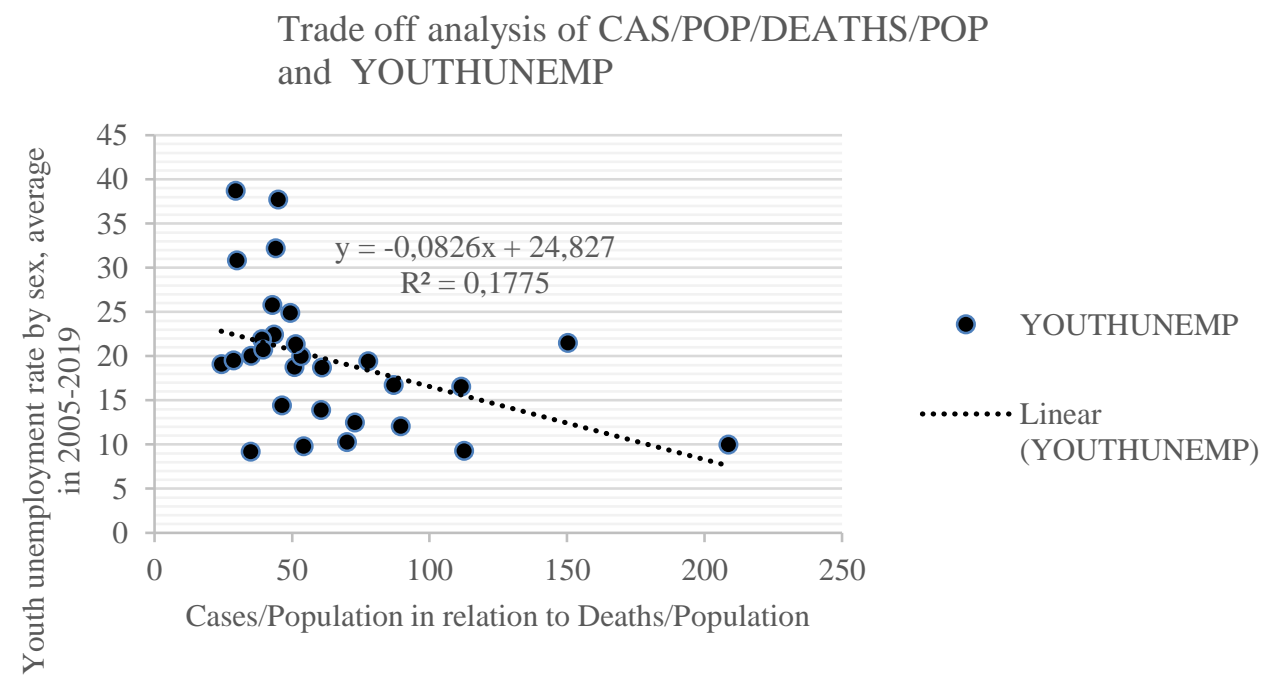

Fig. 5. Youth unemployment rate by sex, average, in 2005-2019 and Cases/Population to Deaths/Population (Source: Eurostat 2021 and ECDP 2021)

We can observe a positive slope between these two variables, the average youth unemployment rate by sex, in 2005-2019, and the variable of Covid-19 Cases/Population to Deaths/Population (Fig. 5). In general, this observation means that in Europe, a higher youth unemployment rate seems to drive Covid19 cases and deaths per population. In Fig. 6, we report a trade-off analysis between the average gender employment gap, in 2005-2019, and the variable Covid-19 Cases/Population to Deaths/Population.

Trade off analysis of CAS/POP/DEATHS/POP and GENDEREMPGAP

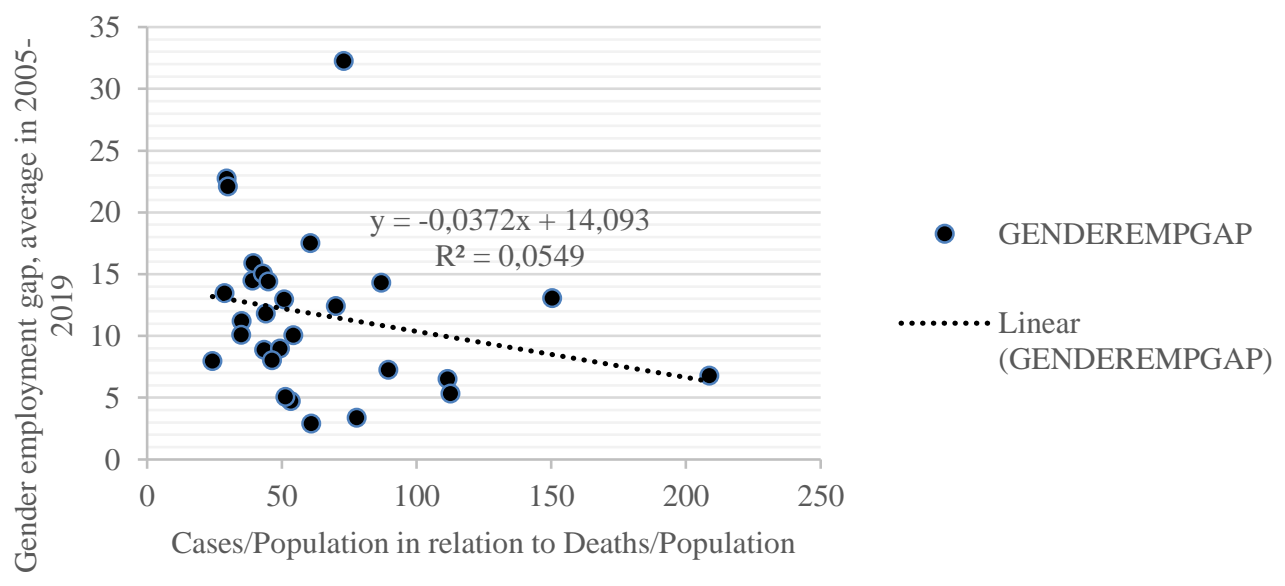

Fig. 6. Gender employment gap, average, in 2005-2019 and Cases/Population to the variable Covid-19 Cases/Population to Deaths/Population (Source: Eurostat 2021 and ECDP 2021) 
We can observe a negative slope between these two variables; the average gender employment gap, in 2005-2019, and the variable of Cases/Population to Deaths/Population (Fig. 6). In general, this observation means that in Europe, the lower gender employment gap drives the variable Covid-19 Cases/Population to Deaths/Population slightly down. However, this result has a very weak statistical significance level, and we cannot take it as the final conclusion. There is a need to make more detailed analyses about this complex issue, which is not having a linear statistical relationship. There are many European countries that have a high gender gap, but quite low Covid-19 deaths per population. Such outlier countries are Malta and Greece, for example. There can also be some measurement problems in these cases. At least we can hesitate measurement errors.

We can observe a negative slope between the following two variables: the average long-term unemployment rate by sex, in 2005-2019 to a variable Covid-19 Cases/Population to Deaths/Population (Fig. 7). In general, this observation means that in Europe, the long-term unemployment rate by sex drives the variable Covid-19 Cases/Population to Deaths/Population variable down. Statistically, this result is not very strong, just a rough indicative result, because we can observe some outliers like Greece in Fig. 7.

\section{Trade off analysis of CAS/POP/DEATHS/POP} and LONGTERMEMP

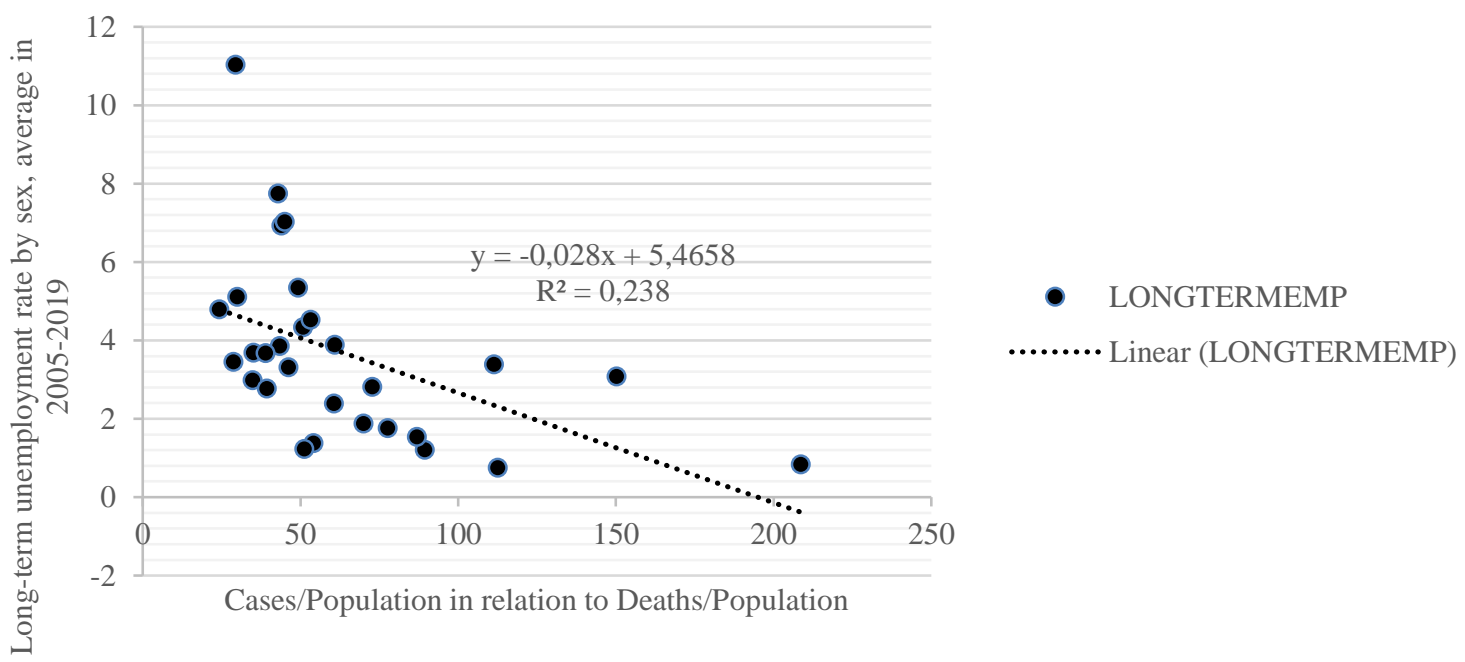

Fig. 7. Long-term unemployment rate by sex, average, in 2005-2019 and Cases/Population to Deaths/Population (Source: Eurostat 2021 and ECDP 2021)

\section{Section 3. Critical Trade-Offs: Education, Social Inclusion and Covid-19 Cases and Deaths}

A positive slope between these two variables: the average adult participation in learning by sex, in 20002019, and the variable of Cases/Population to Deaths/Population (Fig. 8), can be observed. In general, this empirical observation means that in Europe, adult participation in learning decreases Covid-19 deaths per population. Low participation in learning is a driver of Covid-19 Deaths/Population. Again, we can observe some out-layers in Fig. 8. 


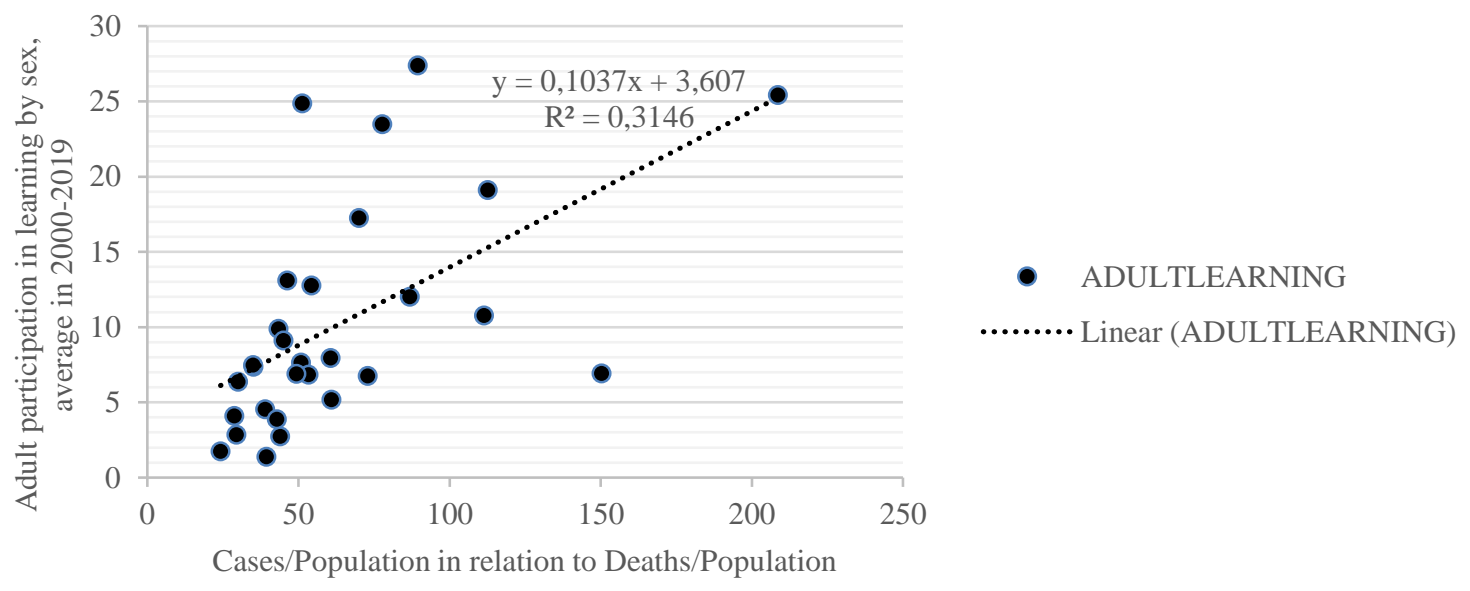

Fig. 8. Adult participation in learning by sex, average, in 2000-2019 and Cases/Population to Deaths/Population (Source: Eurostat 2021 and ECDP 2021)

In Fig. 9, neither a positive nor a negative slope between these two variables, percentage of the population with at least upper secondary educational attainment, age group 25-64, and Cases/Population to Deaths/Population, cannot be observed (Fig. 9). Scientifically we can conclude that secondary education attainment is not a strong driver for Covid-19 cases and deaths.

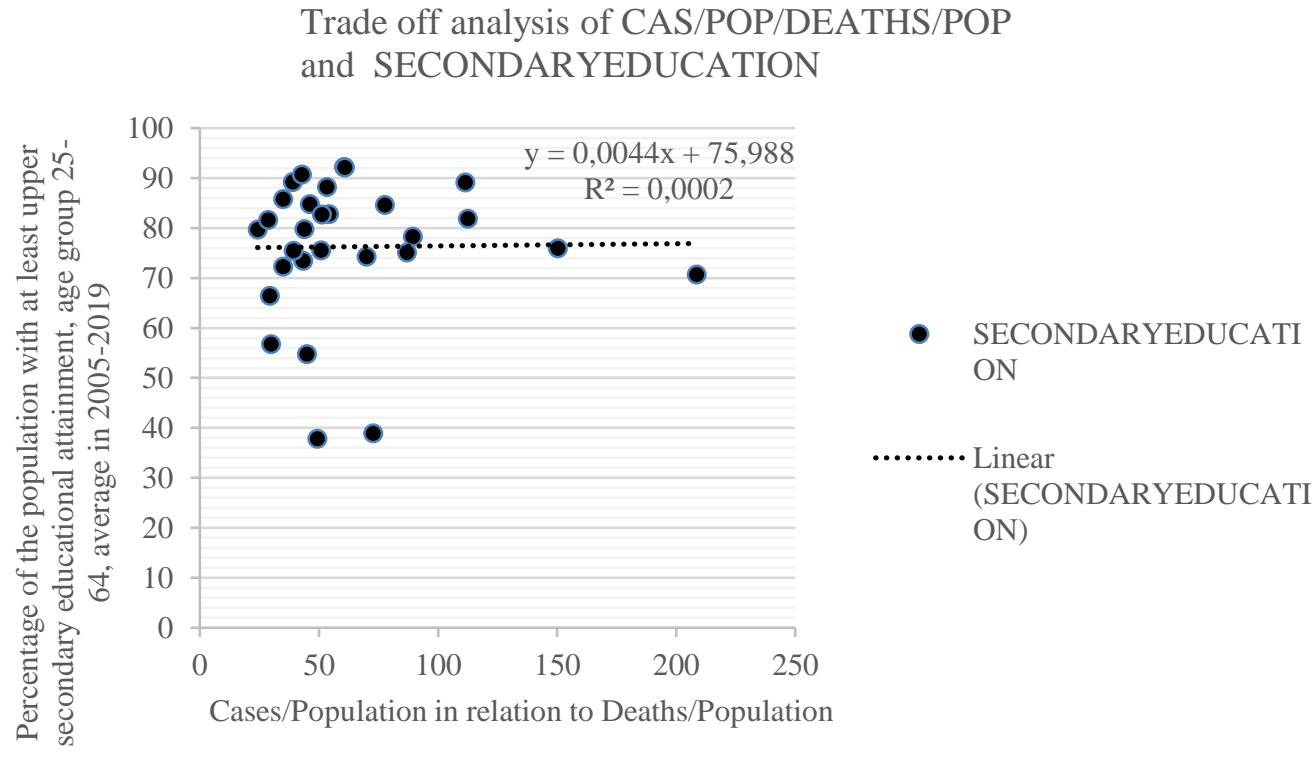

Fig. 9. Percentage of the population with at least upper secondary educational attainment, age group 25 64, average, in 2005-2019, and Cases/Population to Deaths/Population (Source: Eurostat 2021 and ECDP 2021)

A positive slope between the following two variables: tertiary educational attainment, age group 30-34, average in 2005-2019, and the variable of Cases/Population to Deaths/Population, can be observed. (Fig. 10). In general, this empirical observation means that in Europe, tertiary educational attainment predisposes, to some extent, Covid-19 diseases, cases, and deaths per population. Tertiary educational 
attainment is a driver for a higher number Covid-19 cases and deaths. However, some out-layers can be observed in Fig. 10, as well.

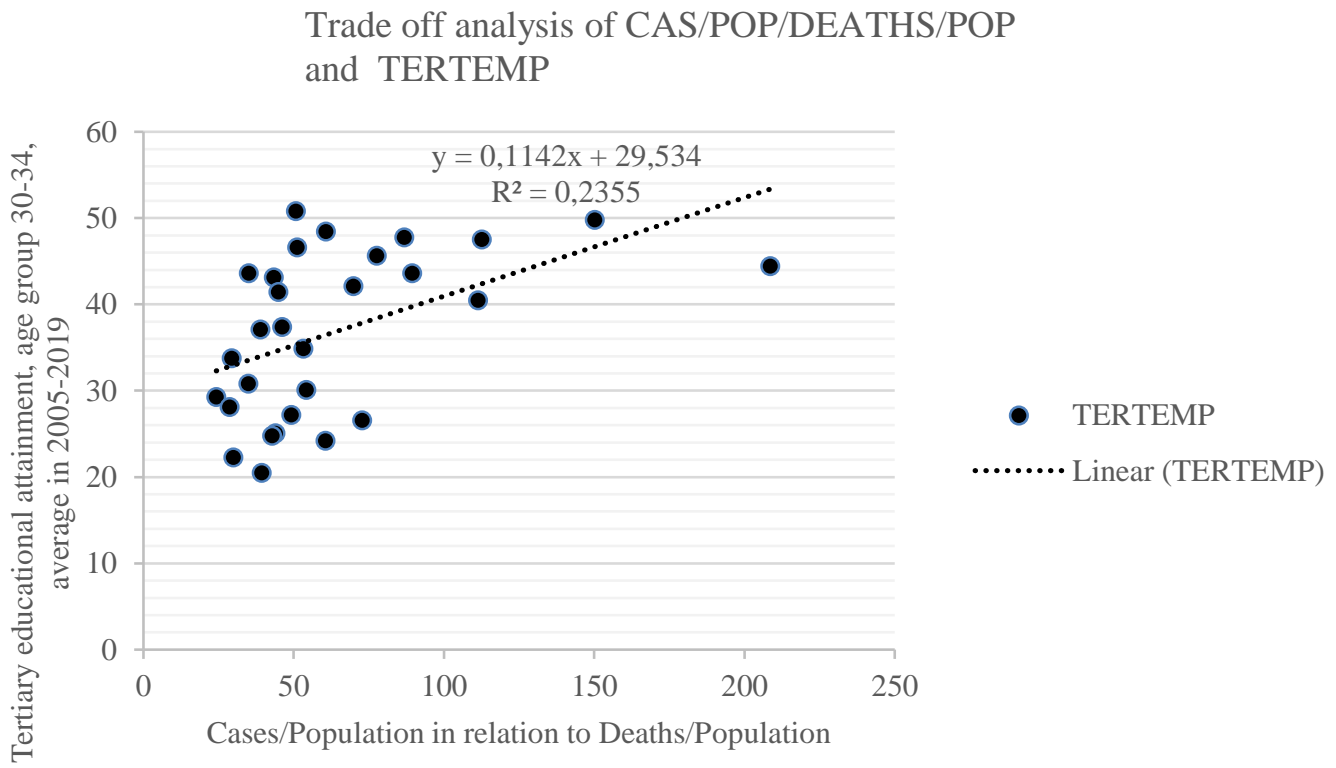

Fig. 10. Tertiary educational attainment, age group 30-34, average, in 2005-2019, and Cases/Population to Deaths/Population (Source: Eurostat 2021 and ECDP 2021)

The educated guess for this result is that the mobility of those with higher education is higher than the mobility of those with lower education. This fact is apparently behind the result.

\section{Section 4. Critical Trade-Offs: Income and Quality of Life, Social Inclusion and Cases/Population to Deaths/Population}

A positive slope between these two key variables, median income by a broad group of citizens, average in 2011-2019, and the variable of Cases/Population to Deaths/Population, can be observed (Fig. 11). In general, this empirical observation means that in Europe, a higher average income increases, to some extent, the number of Covid-19 cases and deaths. The high-income level is a driver for a higher number of Covid-19 cases and deaths to the population. What is interesting in Fig. 11, we can see a non-linear S-curve. Again, we can observe some out-layers in Fig. 11. If we exclude them from the sample, the Scurve hypothesis seems to be quite a realistic hypothesis. The trade-off curve is not very linear in this case. By removing a few extremes from the scattering pattern figure, we might see a fairly linear relationship between the transducers. 


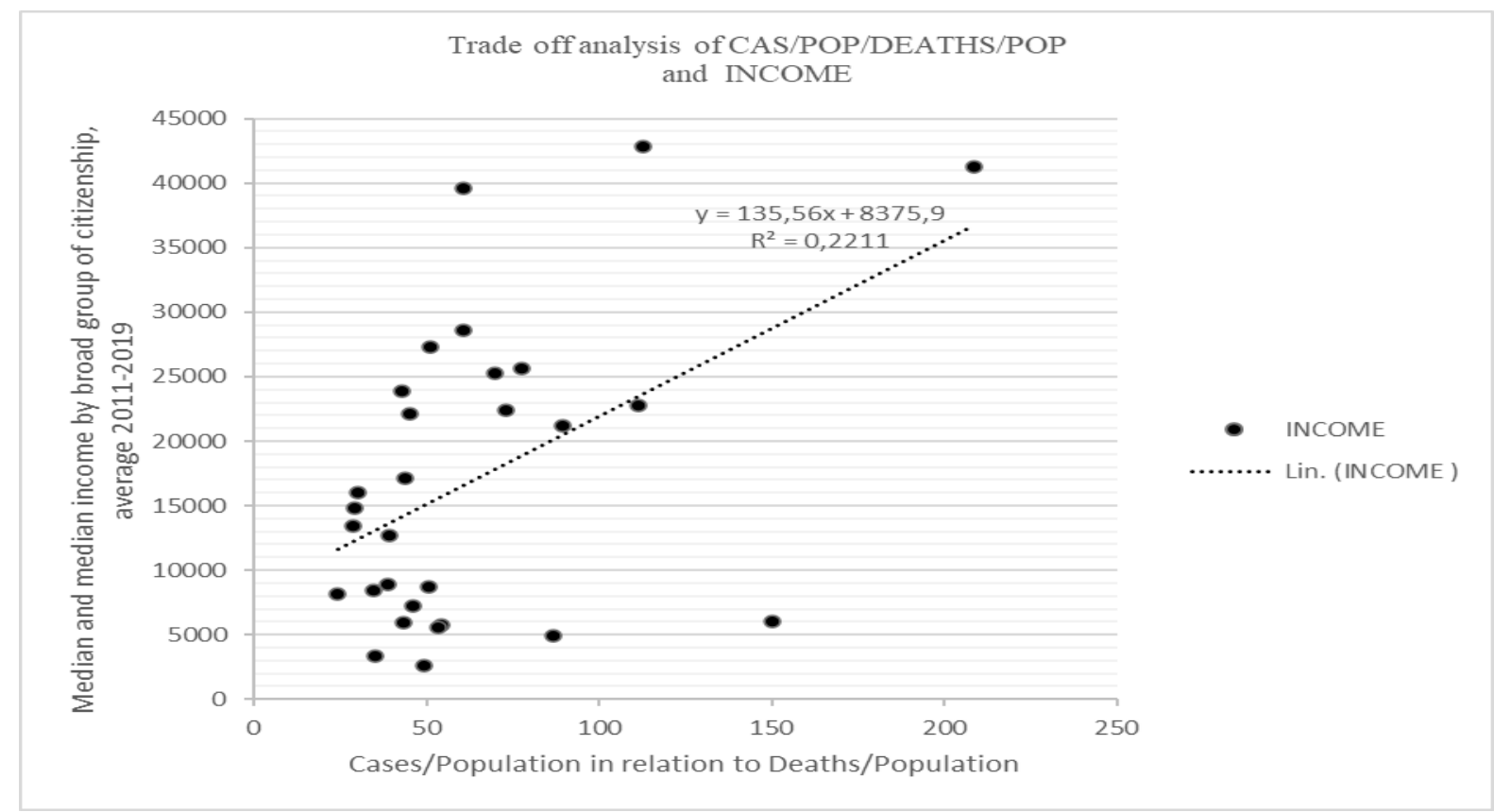

Fig. 11. Median income by a broad group of citizens, average in 2011-2019 and Cases/Population to Deaths/Population (Source: Eurostat 2021 and ECDP 2021)

A positive slope between these two variables, the average life expectancy by age and sex and Covid-19 Deaths/ Population, can be observed. (Fig. 12). In general, this observation means that in Europe, higher life expectancy by age increases, to some extent, the number of Covid-19 cases and deaths. National high life expectancy by age is a driver for a higher number of Covid-19 cases and deaths, too. Again, some out-layers can be observed in Fig. 12.

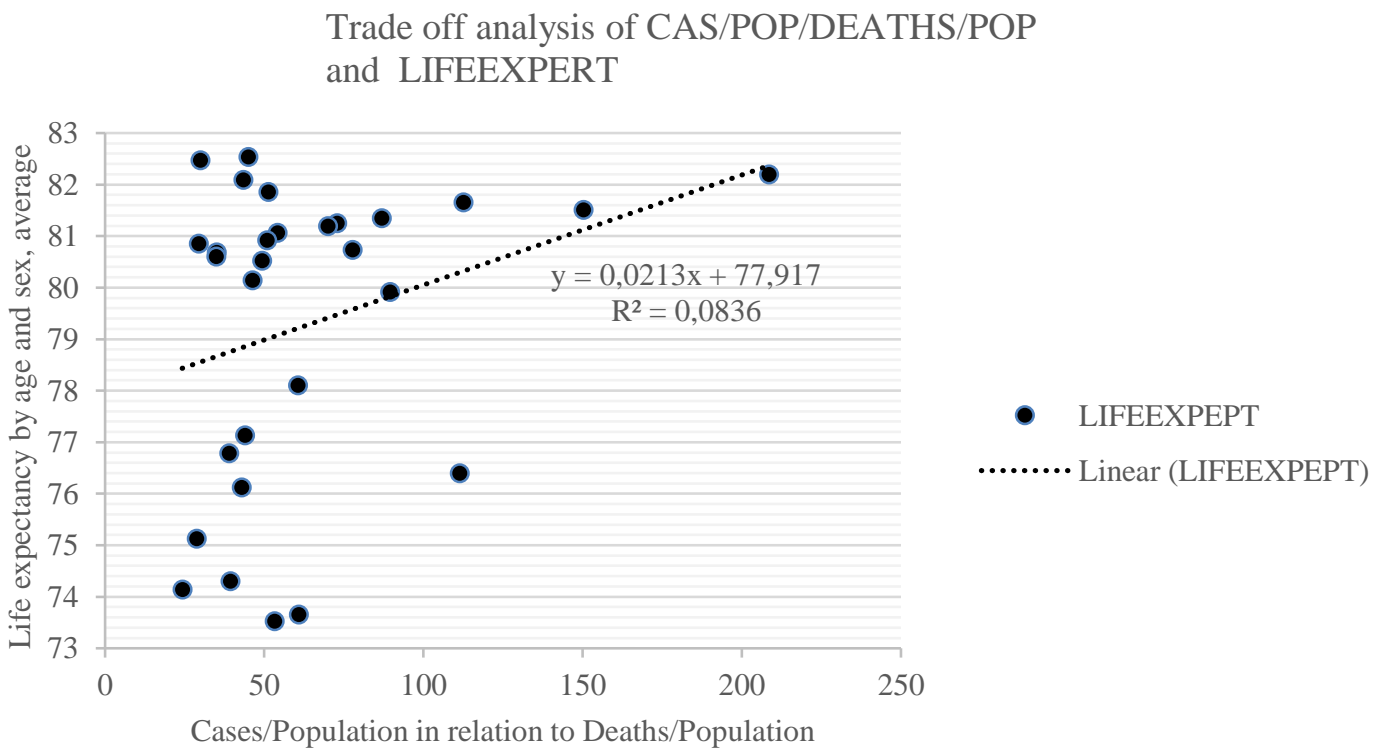

Fig. 12. Life expectancy by age and sex, average, and Cases/Population to Deaths/Population (Source: Eurostat 2021 and ECDP 2021) 
We can observe a stable slope between these two variables, the tax rate on low-wage earners - the unemployment trap, average, in 2005-2010, and the variable Cases/Population to Deaths/Population (see Fig. 13). In general, this observation means that in Europe, the high tax rate on low-wage earners does not have much positive or negative impact on the number of Covid-19 cases and deaths to population. The high tax rate on low-wage earners is a neutral driver for Covid-19 cases and deaths to the population. Again, we can observe some out-layers in Fig. 13.

Trade off analysis of CAS/POP/DEATHS/POP and LOWWAGETAX

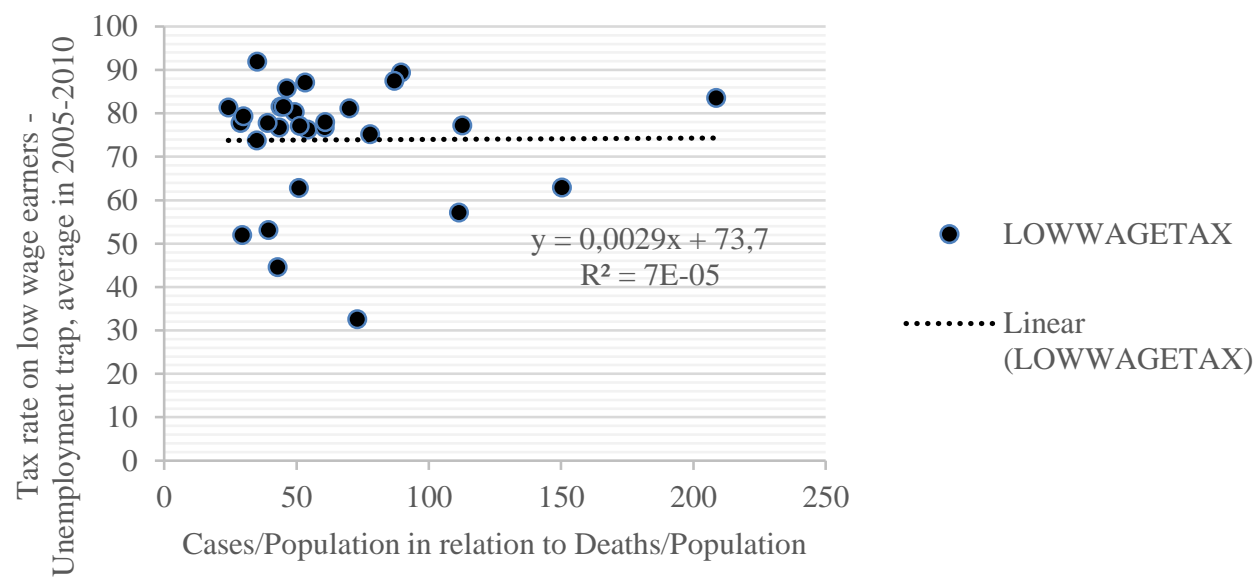

Fig. 13. The tax rate on low wage earners - unemployment trap, average, in 2005-2010 and Cases/Population to Deaths/Population (Source: Eurostat 2021 and ECDP 2021)

A negative slope between the following two variables, severe housing deprivation rate by tenure status, average in 2005-2019, and the variable Cases/Population to Deaths/Population, can be observed (Fig. 14). In general, this observation means that the severe housing deprivation rate by tenure status in Europe decreases to some extent Covid-19 cases and deaths to population. Severe housing deprivation rate by tenure status is a negative trend driver for Covid-19 cases and deaths to the population. Again, some out-layers can be observed in Fig. 13. Statistically, this severe housing deprivation driver is not a very strong driver variable to Covid-19 deaths and cases.

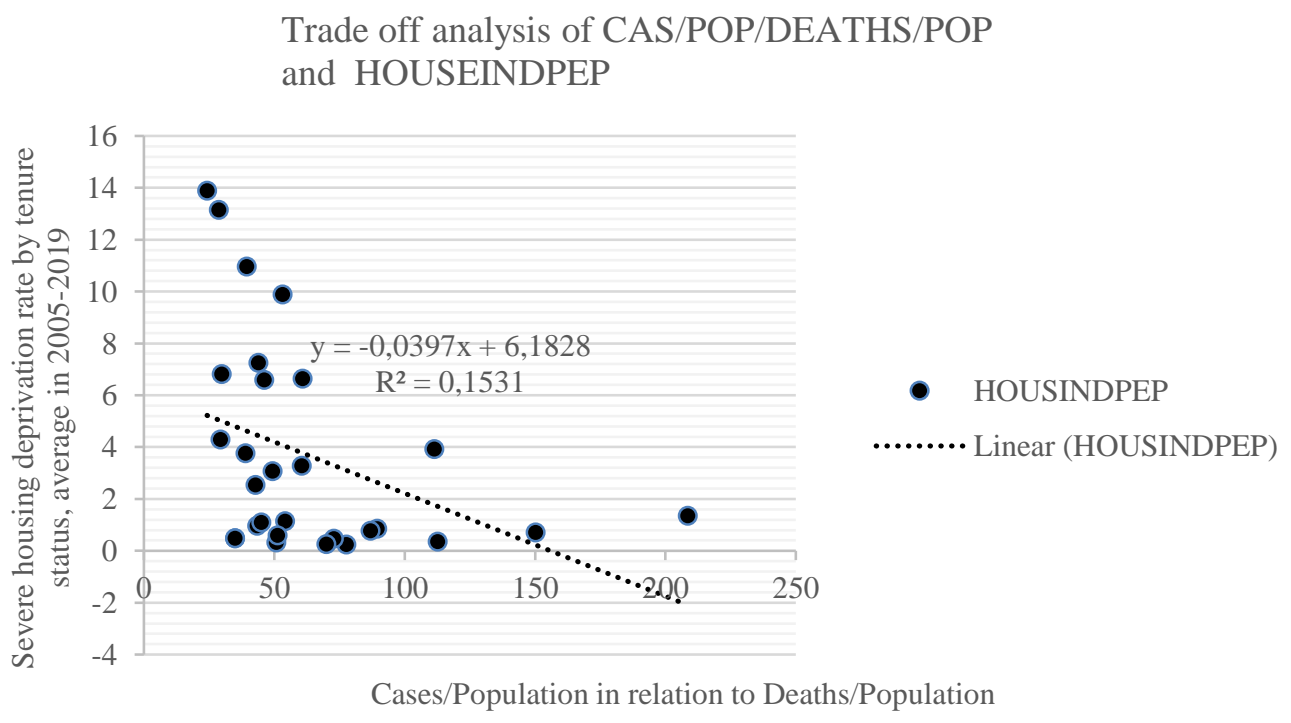

Fig. 14. Severe housing deprivation rate by tenure status, average, in 2005-2019, and Cases/Population to Deaths/Population (Source: Eurostat 2021 and ECDP 2021) 
Section 5. Critical trade-offs: Poverty, social inclusion, material deprivation, and Covid-19 deaths/Population

A negative slope between these two variables, material deprivation rate by sex, average in 2011-2019, and the number of Covid-19 Cases/Population to Deaths/Population, can be observed (Fig. 15). In general, this empirical observation means that the material deprivation rate in Europe, to some extent, decreases the number of Covid-19 cases and deaths per population. High material deprivation rate is a negative driver for Covid-19 deaths/Population. Again, some out-layers can be observed in Fig. 15. Statistically, this severe housing deprivation driver is not a very strong trend driver. Again, some distant out-layers can be observed in Fig. 15.

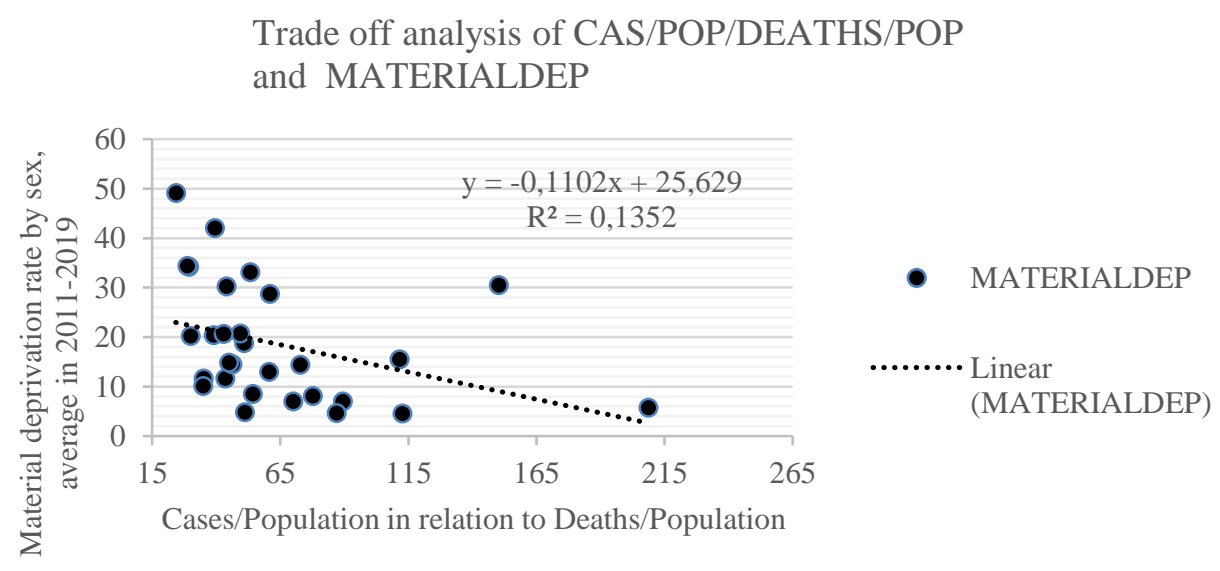

Fig. 15. Material deprivation rate by sex, average in 2011-2019 and Covid-19 Deaths/ Population (Source: Eurostat 2021 and ECDP 2021)

A negative slope between these two variables, persistent at-risk-of-poverty rate by age group, average in 2009-2019, and the variable Covid-19 Deaths/Population, can be observed (Fig. 16). In general, this observation means that in Europe, the persistent at-risk-of-poverty rate is negatively linked, to decreases in the number of Covid-19 cases and deaths per total population. Thus, the persistent at-risk-of-poverty rate is a negative driver for Covid-19 cases and deaths to the population. Again, some out-layers can be seen in Fig. 16. Statistically, this social inclusion driver is not a very strong trend driver.

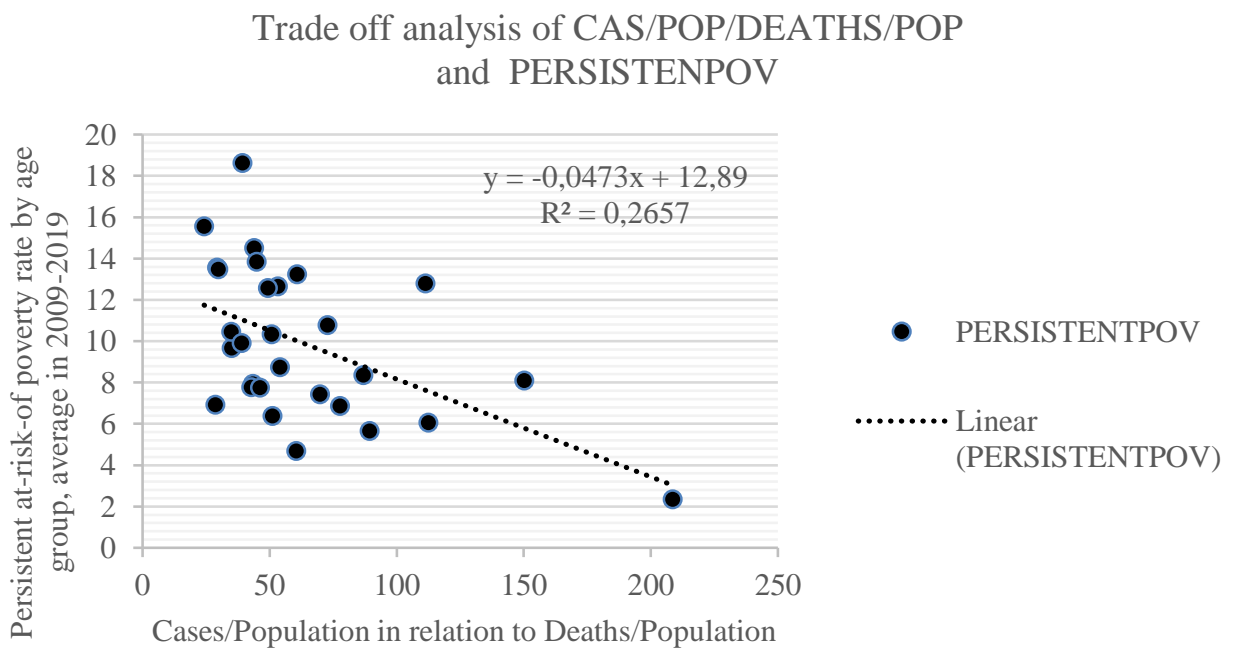

Fig 16. Persistent at-risk-of-poverty rate by age group, average in 2009-2019 and Covid-19 Deaths/ Population (Source: Eurostat 2021 and ECDP 2021) 
A slightly positive slope between these two variables, at-risk-of-poverty rate by a broad group of citizens and Covid-19 Deaths/Population, can be observed (Fig. 17). In other words, this empirical observation means that in Europe, a low at-risk-of-poverty rate by a broad group of citizens, to some extent, decreases the number of Covid-19 cases and deaths to the population. Thus, a variable at-risk-of-poverty rate by a broad group of citizens is a negative driver for Covid-19 cases and deaths to the population (Fig. 17). Again, some out-layers can be observed in Fig. 17.

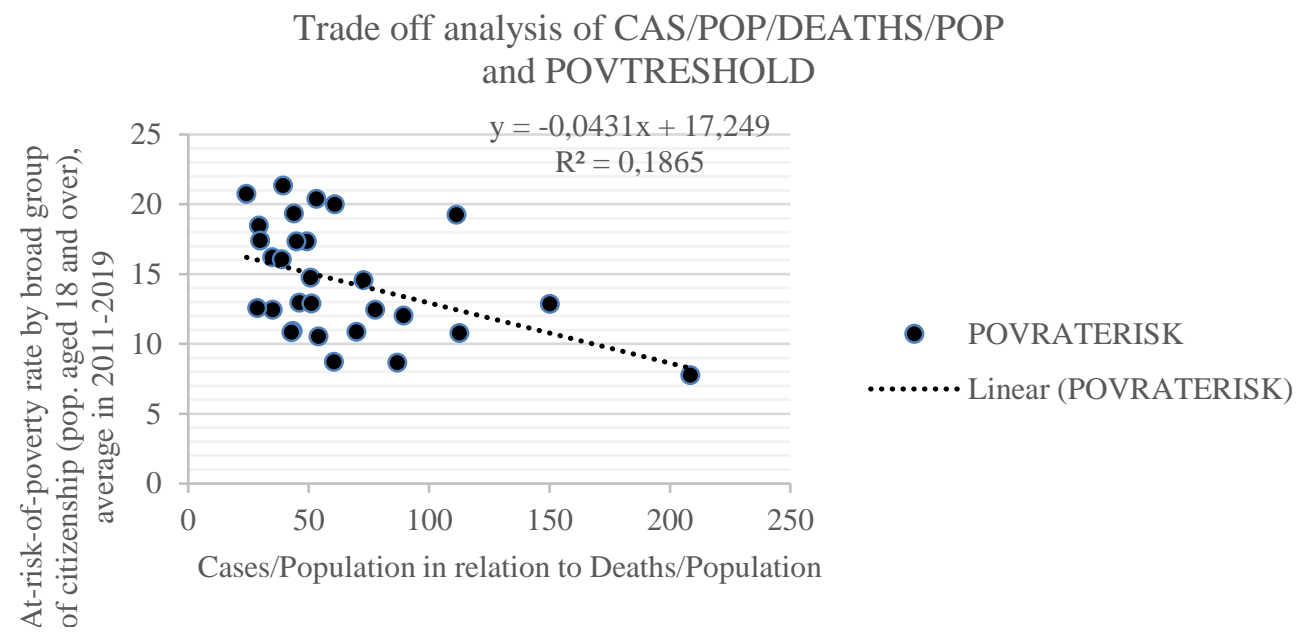

Fig. 17. At-risk-of-poverty rate by a broad group of citizens (pop. aged 18 and over), average in 20112019, and Covid-19 Deaths/ Population (Source: Eurostat 2021 and ECDP 2021)

In Fig. 18, a slightly positive slope between the following two variables, at-risk-of-poverty threshold, average in 2013-2019, and Covid-19 Deaths/Population, can be detected (Fig. 18). In general, this observation means that in Europe, the variable of at-risk-of-poverty threshold to some level increases the number of Covid-19 cases and deaths to population. Thus, a variable at-risk-of-poverty threshold is a positive driver for Covid-19 cases and deaths to the population. Again, some out-layers can be observed in Fig. 18.

Trade off analysis of INEQ-INCOME and POVTRESHOLD

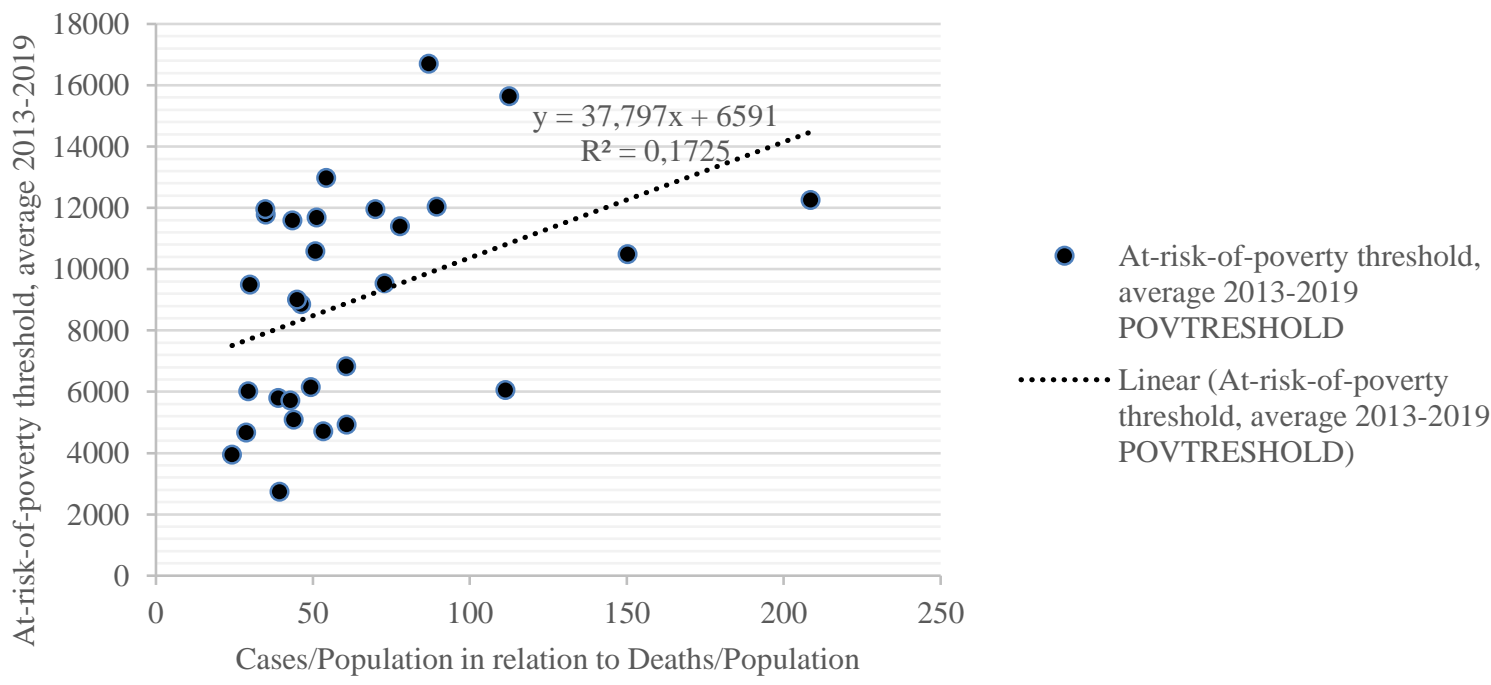

Fig. 18. At-risk-of-poverty threshold, average in 2013-2019 and Covid-19 deaths/ Population (Source: Eurostat 2021 and ECDP 2021) 
In Fig. 19, a negative slope between two variables, at-risk-of-poverty rate of households with at least one dependent child by work intensity, average in 2009-2019, and Covid-19 Deaths/Population, can be observed. The linear relationship between the two variables is not very strong.

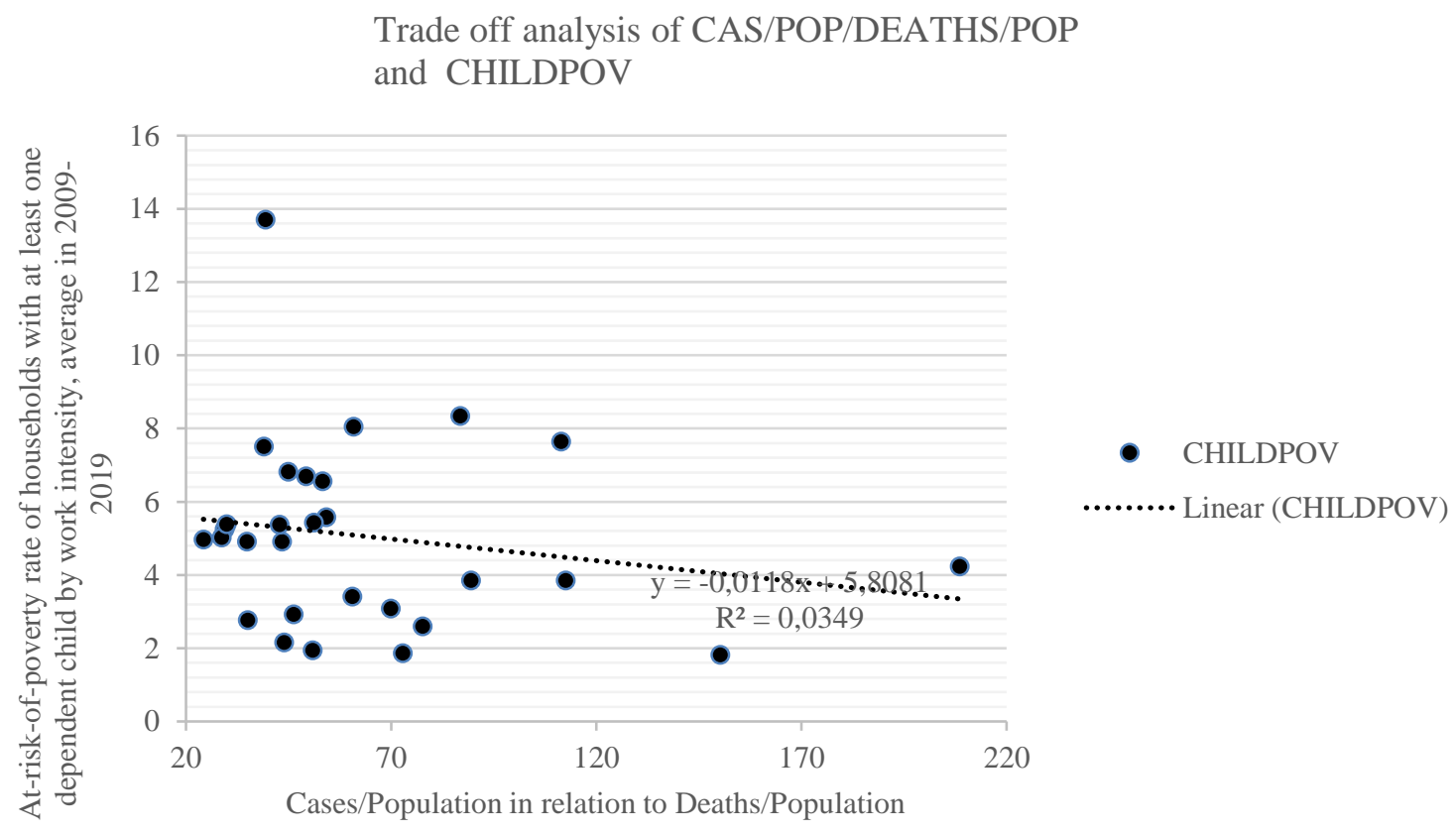

Fig. 19. At-risk-of-poverty rate of households with at least one dependent child by work intensity, average in 2009-2019 and Covid-19 Deaths/ Population (Source: Eurostat 2021 and ECDP 2021)

In Table 1, we report key results and findings of our drivers-driven trend study.

Table 1. Social inclusion and trade-off analysis with Covid-19 deaths. Potentiality of social inclusion drivers leading to Covid-19 Deaths/Population.

\begin{tabular}{|l|l|c|c|}
\hline $\begin{array}{l}\text { Social inclusion variables, } \\
\text { Source Eurostat 2021 social } \\
\text { inclusion variables }\end{array}$ & $\begin{array}{l}\text { The nature of social inclusion driver to Covid-19 } \\
\text { Deaths/ Population }\end{array}$ & $\begin{array}{l}\text { Power of } \\
\text { driver }\end{array}$ & $\begin{array}{c}\text { Out- } \\
\text { layers }\end{array}$ \\
\hline $\begin{array}{l}\text { 1.Gini coefficient, average in } \\
\text { 2009-2019 (Fig. 2) }\end{array}$ & $\begin{array}{l}\text { Not the driver in any direction (Covid-19 cases and } \\
\text { deaths). Statistically not a significant relationship. }\end{array}$ & Weak & Many \\
\hline $\begin{array}{l}\text { 2. Inequality of income } \\
\text { distribution, average in 2009- } \\
\text { 2019 (Fig. 3) }\end{array}$ & $\begin{array}{l}\text { Less inequality of income distribution can lead to } \\
\text { more Covid -19 cases and deaths to the population. } \\
\text { Statistically not a significant relationship. }\end{array}$ & Average & Some \\
\hline $\begin{array}{l}\text { 3.Employment rate of older } \\
\text { workers, age group 55-64, } \\
\text { average in 2005-2019 (Fig 4) }\end{array}$ & $\begin{array}{l}\text { The employment rate of older workers leads to } \\
\text { more Covid -19 cases and deaths to population. } \\
\text { Statistically not a significant relationship. }\end{array}$ & Strong & Some \\
\hline $\begin{array}{l}\text { 4. Youth unemployment rate } \\
\text { by sex, average in 2005-2019 } \\
\text { (Fig. 5) }\end{array}$ & $\begin{array}{l}\text { The youth unemployment rate can decrease the } \\
\text { number of Covid-19 cases and deaths to the } \\
\text { population. The driver is not very strong. } \\
\text { Statistically significant social inclusion variable. }\end{array}$ & Average & Some \\
\hline $\begin{array}{l}\text { 5.Gender employment gap, } \\
\text { average in 2005-2019 (Fig. 6) }\end{array}$ & $\begin{array}{l}\text { The gender employment gap slightly increases the } \\
\text { number of Covid-19 cases and deaths to the } \\
\text { population. Not very strong trend driver. } \\
\text { Statistically not significant social inclusion } \\
\text { variable. }\end{array}$ & Weak & Quite \\
many
\end{tabular}




\begin{tabular}{|c|c|c|c|}
\hline $\begin{array}{l}\text { 7.Adult participation in } \\
\text { learning by sex, average in } \\
2000-2019 \text { (Fig. } 8 \text { ) }\end{array}$ & $\begin{array}{l}\text { The long-term unemployment rate can increase the } \\
\text { number of Covid-19 and cases of deaths to the } \\
\text { population. The driver is quite strong. Statistically } \\
\text { significant social inclusion variable. }\end{array}$ & Medium & Some \\
\hline $\begin{array}{l}\text { 8.Percentage of the population } \\
\text { with at least upper secondary } \\
\text { educational attainment, age } \\
\text { group 25-64 (Fig. 9) }\end{array}$ & $\begin{array}{l}\text { Not a trend driver to negative or positive direction } \\
\text { concerning Covid-19 cases and deaths. The driver } \\
\text { is very weak. Statistically not significant social } \\
\text { inclusion variable. }\end{array}$ & Weak & Many \\
\hline $\begin{array}{l}\text { 9.Tertiary educational } \\
\text { attainment, age group } 30-34 \text {, } \\
\text { average in 2005-2019 (Fig. } \\
\text { 10) }\end{array}$ & $\begin{array}{l}\text { The long-term unemployment rate can increase the } \\
\text { number of Covid-19 cases and deaths into the } \\
\text { population. Trend driver is quite strong. } \\
\text { Statistically significant social inclusion variable. }\end{array}$ & Medium & Some \\
\hline $\begin{array}{l}\text { 10.Median income by a broad } \\
\text { group of citizens, average } \\
\text { 2011-2019 (Fig. 11) }\end{array}$ & $\begin{array}{l}\text { Median income can decrease the number of Covid- } \\
19 \text { cases and deaths to population. Trend driver is } \\
\text { quite strong. Statistically significant social inclusion } \\
\text { variable. }\end{array}$ & Medium & Some \\
\hline $\begin{array}{l}\text { 11. Life expectancy by age } \\
\text { and sex, average (Fig. 12) }\end{array}$ & $\begin{array}{l}\text { Life expectancy by age and sex can increase the } \\
\text { number of Covid-19 cases and deaths to population. } \\
\text { This trend driver is weak. Statistically significant } \\
\text { social inclusion variable. }\end{array}$ & Weak & Some \\
\hline $\begin{array}{l}\text { 11.Tax rate on low wage } \\
\text { earners - unemployment trap, } \\
\text { average in 2005-2010 (Fig. } \\
\text { 13) }\end{array}$ & $\begin{array}{l}\text { The tax rate on low-wage earners (unemployment } \\
\text { trap) does not have a direct impact on the number of } \\
\text { Covid- } 19 \text { cases and deaths to the population. } \\
\text { Statistically not a significant variable. }\end{array}$ & Weak & Some \\
\hline $\begin{array}{l}\text { 12.Severe housing deprivation } \\
\text { rate by tenure status, average } \\
\text { in } 2005-2019 \text { (Fig. 14) }\end{array}$ & $\begin{array}{l}\text { Severe housing deprivation rate by tenure status can } \\
\text { decrease the number of Covid-19 cases and deaths to } \\
\text { population. This trend driver is a strong but } \\
\text { statistically not significant social inclusion variable. } \\
\text { Requires more further investigations because this } \\
\text { social inclusion variable plays a different role in } \\
\text { different EU countries. }\end{array}$ & Medium & Many \\
\hline $\begin{array}{l}\text { 13.Material deprivation rate } \\
\text { by sex, average in 2011-2019 } \\
\text { (Fig .15) }\end{array}$ & $\begin{array}{l}\text { Lower material deprivation rate can decrease the } \\
\text { number of Covid- } 19 \text { cases and deaths to population. } \\
\text { This trend driver is weak. Statistically significant } \\
\text { social inclusion variable. }\end{array}$ & Weak & Many \\
\hline $\begin{array}{l}\text { 14.Persistent at-risk-of- } \\
\text { poverty rate by age group, } \\
\text { average in 2009-2019 (Fig.16) }\end{array}$ & $\begin{array}{l}\text { The persistent at-risk-of-poverty rate can decrease } \\
\text { the number of Covid- } 19 \text { cases and deaths to the } \\
\text { population. This trend driver is weak. Statistically } \\
\text { significant social inclusion variable. }\end{array}$ & Medium & Many \\
\hline $\begin{array}{l}\text { 15.At-risk-of-poverty rate by a } \\
\text { broad group of citizens (pop. } \\
\text { aged } 18 \text { and over), average in } \\
2011-2019 \text { (Fig. 17) }\end{array}$ & $\begin{array}{l}\text { At-risk-of-poverty rate by a broad group of citizens, } \\
\text { to a minor extent, increases the number of Covid- } 19 \\
\text { cases and deaths to population. This trend driver is } \\
\text { having a medium impact. Statistically significant } \\
\text { social inclusion variable. }\end{array}$ & Medium & Many \\
\hline $\begin{array}{l}\text { 16.At-risk-of-poverty } \\
\text { threshold, average 2013-2019 } \\
\text { (Fig. 18) }\end{array}$ & $\begin{array}{l}\text { At-risk-of-poverty threshold variable can decrease } \\
\text { the number of Covid- } 19 \text { cases and deaths to } \\
\text { population. This trend driver is quite strong. } \\
\text { Statistically significant social inclusion variable. }\end{array}$ & Medium & Some \\
\hline $\begin{array}{l}\text { 17.At-risk-of-poverty rate of } \\
\text { households with at least one } \\
\text { dependent child by work } \\
\text { intensity, average in 2009- } \\
2019 \text { (Fig. 19) }\end{array}$ & $\begin{array}{l}\text { At-risk-of-poverty rate of households with at least } \\
\text { one dependent child by work intensity can slightly } \\
\text { increase Covid- } 19 \text { death rate to population. This } \\
\text { trend driver is weak. Statistically not significant } \\
\text { social inclusion variable. }\end{array}$ & Weak & Many \\
\hline
\end{tabular}

We have also made a correlation analysis. In Table 2.a. and 2.b the Pearson correlation coefficients (PCC) are reported, also referred to as Pearson's $r$, the Pearson product-moment correlation coefficient (PPMCC), or the bivariate correlation. It is a measure of linear correlation between two sets of data (see Nummenmaa et al. 2017, chapter 8). Tables 2.a. and 2.b include key results of statistical bivariate correlation analysis. It reveals key statistical correlation analysis results. We marked statistically 
significant variables with grey colour and not significant variables with no colour in Table $2 \mathrm{a}$ and Table $2 b$.

Table 2.a. Correlation analysis of key Covid-19 and social inclusion variables. Data of 29 European countries.

\begin{tabular}{|c|c|c|c|c|c|c|}
\hline & & PERSISTENTPOV & CHILDPOV & INCOME & LIFEEXPEPT & LOWWAG \\
\hline & Cases & 0,13 & 0,15 & $-0,19$ & 0,30 & 0,17 \\
\hline Two-sided t-test & CAS & & & & & \\
\hline \multicolumn{7}{|l|}{ One-sided t-test } \\
\hline & & & & & & \\
\hline & Deaths & 0,20 & 0,16 & $-0,22$ & 0,27 & 0,16 \\
\hline Two-sided t-test & DEATHS & & & & & \\
\hline \multicolumn{7}{|l|}{ One-sided t-test } \\
\hline & & & & & & \\
\hline & \multicolumn{2}{|c|}{ Cases/Pop(Deaths/P } & 0,16 & $-0,45$ & $-0,30$ & 0,02 \\
\hline Two-sided t-test & \multicolumn{2}{|c|}{ CAS/POP/DEATHS/POP } & & & & \\
\hline One-sided t-test & & HOUSINDPEP & EMPRATE & EMPOLDWORKERS & YOUTHUNEMP & GENDEREI \\
\hline & & & & & & \\
\hline & Cases & $-0,12$ & $-0,24$ & $-0,18$ & 0,30 & 0,17 \\
\hline Two-sided t-test & CAS & & & & & \\
\hline \multicolumn{7}{|l|}{ One-sided t-test } \\
\hline & & & & & & \\
\hline & Deaths & $-0,03$ & $-0,30$ & $-0,21$ & 0,32 & 0,21 \\
\hline Two-sided t-test & DEATHS & & & & & \\
\hline \multicolumn{7}{|l|}{ One-sided t-test } \\
\hline & & & & & & \\
\hline & \multicolumn{2}{|c|}{ Cases/Pop(Deaths/P } & $-0,67$ & $-0,54$ & 0,47 & 0,26 \\
\hline Two-sided t-test & \multicolumn{2}{|c|}{ CAS/POP/DEATHS/POP } & & & & \\
\hline One-sided t-test & & LONGTERMEMP & TERTEMP & ADULTLEARNING & \multicolumn{2}{|c|}{ SECONDARYEDUCATION } \\
\hline & & & & & & \\
\hline & Cases & 0,16 & $-0,16$ & $-0,16$ & $-0,21$ & \\
\hline Two-sided t-test & CAS & & & & & \\
\hline \multicolumn{7}{|l|}{ One-sided t-test } \\
\hline & & & & & & \\
\hline & Deaths & 0,19 & $-0,23$ & $-0,21$ & $-0,22$ & \\
\hline Two-sided t-test & DEATHS & & & & & \\
\hline \multicolumn{7}{|l|}{ One-sided t-test } \\
\hline & & & & & & \\
\hline & \multicolumn{2}{|c|}{ Cases/Pop(Deaths/P } & $-0,54$ & $-0,62$ & $-0,06$ & \\
\hline Two-sided t-test & \multicolumn{2}{|c|}{ CAS/POP/DEATHS/POP } & & & & \\
\hline One-sided t-test & & & & & & \\
\hline
\end{tabular}

Table 2.b. Correlation analysis of key Covid-19 and social inclusion variables. Data of 29 European countries.

\begin{tabular}{|c|c|c|c|c|c|c|c|}
\hline & & & DEATHS & POP & CAS/POP & DEATHS/POP & CAS/POP/ \\
\hline & & & & & & & \\
\hline & Cases & & 0,97 & 0,93 & 0,16 & 0,38 & $-0,38$ \\
\hline Two-sided t-test & CAS & $\mathrm{p}$-value & & & & & \\
\hline \multicolumn{8}{|l|}{ One-sided t-test } \\
\hline & & & & & & & \\
\hline & Deaths & & & 0,95 & 0,07 & 0,38 & $-0,40$ \\
\hline Two-sided t-test & DEATHS & $p$-value & & & & & \\
\hline \multicolumn{8}{|l|}{ One-sided t-test } \\
\hline & & & & & & & \\
\hline & \multicolumn{3}{|c|}{ Cases/Pop(Deaths/Pop } & 0,41 & 0,00 & 0,61 & $-0,82$ \\
\hline Two-sided t-test & \multicolumn{3}{|c|}{ CAS/POP/p-value } & & & & \\
\hline \multicolumn{8}{|l|}{ One-sided t-test } \\
\hline & & & GINI & INEQ-INCOME & POVTRESHOLD & POVRATERISK & MATERIAL \\
\hline & & & & & & & \\
\hline & Cases & & 0,16 & 0,14 & 0,07 & 0,04 & $-0,14$ \\
\hline Two-sided t-test & CAS & & & & & & \\
\hline \multicolumn{8}{|l|}{ One-sided t-test } \\
\hline & & & & & & & \\
\hline & Deaths & & 0,20 & 0,18 & 0,05 & 0,11 & $-0,08$ \\
\hline Two-sided t-test & DEATHS & & & & & & \\
\hline \multicolumn{8}{|l|}{ One-sided t-test } \\
\hline & & & & & & & \\
\hline & \multicolumn{3}{|c|}{ Cases/Pop(Deaths/P } & 0,41 & $-0,49$ & 0,45 & 0,57 \\
\hline Two-sided t-test & \multicolumn{3}{|c|}{ CAS/POP/DEATHS/POP } & & & & \\
\hline One-sided t-test & & & & & & & \\
\hline
\end{tabular}

In Table 3, we have reported statistical test information. We have tested the significance of correlation coefficients with a significance level of 5\% (1-sided and 2-sided tests). The grey colour in Tables 2.a and 2.b. was used by this statistical test criterion of significance. 
Table 3. Statistical test information

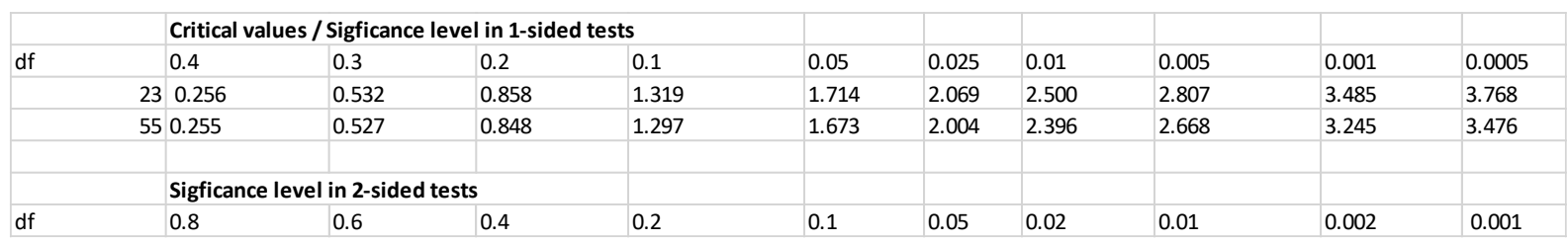

\section{Conclusions}

This empirical study provides some insights into European socio-economic recovery policy after the COVID-19 crisis (so-called exit strategies). It is obvious that paying more attention to social inclusion is needed in the post-Covid-19 crisis era in the European Union. According to our analysis the following variables of social inclusion are in need of special attention in relation to the key variable "Cases/Population in relation to Deaths/Population": (1) Inequality of income distribution, average in 2009-2019, (2) At-risk-of-poverty threshold, average 2013-2019, (3) At-risk-of-poverty rate by broad group of citizens (pop. aged 18 and over), average in 2011-2019, (4) Material deprivation rate by sex, average in 2011-2019, (5) Persistent at-risk-of poverty rate by age group, average in 2009-2019, (6) Median income by broad group of citizens, average 2011-2019, (7) Unemployment trap, average in 2005-2010, (8) Average employment rate by sex, average in 2005-2019, (9) Employment rate of older workers, age group 55-64, average in 2005-2019, (10) Youth unemployment rate by sex, average in 2005-2019, (11) Long-term unemployment rate by sex, average in 2005-2019, (12) Tertiary educational attainment, age group 30-34, average in 2005-2019, and (13) Adult participation in learning by sex, average in 2000-2019. In general, the variables of social inclusion should be taken into account in the debate and decision-making on the COVID-19 issues in the European Commission and the European Parliament as improvements in social inclusion policy decrease vulnerability to pandemic risks.

In this study, we can generally conclude that the relationship between Covid-19 cases and corona-related deaths and social inclusion variables is a challenging research topic where we achieved some interesting findings. Our results are indicative of scientific nature, and more research will be needed if we want to develop more sophisticated statistical prediction models. Many poverty variables of social inclusion are contributing to the incidence of cases and Covid-19 deaths. We can conclude that education, labour market variables, and other welfare variables are statistically linked to the number of Covid-19 cases, and deaths, and also these variables are relevant topics of further investigations. In this study, we identified key social inclusion drivers for Covid-19 cases and deaths in the EU, 29 countries.

We did not find that other social inclusion variables could be strategically as important for COVID-19 phenomena, although they are not entirely meaningless. Of course, there can be indirect and complex relationships, which may have impacts on the COVID-19 phenomena. Correlation Tables $2 \mathrm{a}$ and $2 \mathrm{~b}$ and all figures include more detailed statistical analyses and reveal that some social inclusion variables have a statistically significant relationship to the number of COVID-19 cases and deaths to population variables in the EU-29 region. Naturally, these social inclusion variables need more strategic attention in the social inclusion policy of the European Union, if COVID-19 cases and deaths or another COVID19 type of pandemic deaths to be controlled in the future. The EU planners of national exit strategies of the COVID-19 crisis should be aware of the social inclusion effects. Decision-makers are aware of the potential and real effects of social inclusion factors on Covid-19 deaths and cases.

As usual, a reservation should be added to the results obtained that probably not all corona cases and deaths have been measured in an entirely consistent and scientifically accurate manner. In this study, we have relied on official statistical data sources of the European Union. 


\section{Acknowledgements}

The project "Platforms of Big Data Foresight (PLATBIDAFO)" has received funding from European Regional Development Fund (project No 01.2.2-LMT-K-718-02-0019) under a grant agreement with the Research Council of Lithuania (LMTLT).

\section{References}

Arbolino, R. \& Di Caro, P. (2021) Can the EU funds regional resilience at time of Covid-19? Insights from the Great Recession. Journal of Policy Modeling, 2021, Vol. 43, Issue 1, 109-126. 10.1016/j.jpolmod.2020.10.001

Cacioppo, J. T., \& Cacioppo, S. (2014) Older adults reporting social isolation or loneliness show poorer cognitive function 4 years later. Evidence Based Nursing, 17(2), 59-60. https://doi.org/10.1136/eb-2013-101379

Cudjoe, T. K. M., Roth, D. L., Szanton, S. L., Wolff, J. L., Boyd, C. M., \& Thorpe, R.J.J. (2020) The epidemiology of social isolation: National health and aging trends study. The Journals of Gerontology: Series B, 75(1), 107-113. https://doi.org/10.1093/geronb/gby037

Courtin, E., \& Knapp, M. (2017) Social isolation, loneliness and health in old age: A scoping review. Health \& Social Care in the Community, 25(3), 799-812. https://doi.org/10.1111/hsc.12311

Elgar, F.J., Stefaniak, A. \& Wohl, M.A.A. (2020) The trouble with trust: Time-series analysis of social capital, income inequality, and COVID-19 deaths in 84 countries. Social Science \& Medicine, Volume 263, October 2020, Article 113365. https://doi.org/10.1016/j.socscimed.2020.113365

European Centre for Disease Prevention (2021) Data on 14-day notification rate of new COVID-19 cases and deaths . Web: Publications \& Data | European Centre for Disease Prevention and Control (europa.eu)

Eurostat (2021) Income and Living Conditions. Web: Overview - Income and living conditions - Eurostat (europa.eu)

Hayashi, T., Umegaki, H., Makino, T., Huang, C. H., Inoue, A., Shimada, H., \& Kuzuya, M. (2020) Combined impact of physical frailty and social isolation on rate of falls in older adults. The Journal of Nutrition, Health \& Aging, 24(3), 312-318. https://doi.org/10.1007/s12603-020-1316-5

Mendoza-del Villar, L., Oliva-Lopeza, E., Luis-Pineda, O., Benešová, A., Tupa, J \& Garza-Reyes, J.A. (2020) Fostering economic growth, social inclusion \& sustainability in Industry 4.0: a systemic approach. Procedia Manufacturing, Vol. 51, 1755-1762. https://doi.org/10.1016/j.promfg.2020.10.244

Nummenmaa, L, Holopainen, M. \& Pulkkinen, P. (2017) The Foundations of Statistical Methods. Sanoma Pro. Helsinki. (In Finnish).

Ranjbari, M., Esfandabadi, Z.S., Zanetti, M.C., Scagnelli, D.S., Siebers, P.O., Aghbashlo, M., Peng, W., Quatraro, F. \& Tabatabaei, M. (2021) Three pillars of sustainability in the wake of COVID-19: A systematic review and future research agenda for sustainable development. Journal of Cleaner Production, Vol. 297, Article 126660.https://doi.org/10.1016/j.jclepro.2021.126660.

Schoukens, P., De Becker, E. \& Joris BekeSmets, J.B. (2015) Fighting social exclusion under the Europe 2020 strategy: Which legal nature for social inclusion recommendations? International Comparative Jurisprudence, Vol. 1, Issue 1,11-23. https://doi.org/10.1016/j.icj.2015.10.003

Xie, B., Charness , N., Fingerman, K.,Kaye, J., Kim, M.T. \& Khurshid, A. (2020) When Going Digital Becomes a Necessity: Ensuring Older Adults' Needs for Information, Services, and Social Inclusion During COVID-19, Journal of Aging \& Social Policy, 32:4-5, 460-470. DOI: 10.1080/08959420.2020.1771237 


\section{Appendix 1}

Covid-19-Variables and Social Inclusion Variables in the study

Deaths $=$ DEATHS, Population $=$ POP Cases $/$ Population $=$ CAS $/$ POP, Deaths $/$ Population $=$ DEATHS $/$ POP, Cases $/$ Population in relation to Deaths/Population $=$ CAS/POP/DEATHS/POP, Gini coefficient, average 2009-2019= GINI, Inequality of income distribution, average in 2009-2019 = INEQ-INCOME, At-risk-of-poverty threshold, average 2013-2019= POVTRESHOLD, At-risk-of-poverty rate by broad group of citizenship (pop. aged 18 and over), average in 2011-2019= POVRATERISK, Material deprivation rate by sex, average in 2011-2019 = MATERIALDEP, Persistent at-risk-of poverty rate by age group, average in 2009-2019 = PERSISTENTPOV, At-risk-of-poverty rate of households with at least one dependent child by work intensity, average in 2009-2019 = CHILDPOV, Median and median income by broad group of citizenship, average 2011-2019 $=$ INCOME Life expectancy by age and sex, average $=$ LIFEEXPEPT, Tax rate on low wage earners $=$ LOWWAGETAX, Unemployment trap, average in 2005-2010 = EMPRATE Severe housing deprivation rate by tenure status, average in 20052019= HOUSINDPEP, Average employment rate by sex, average in 2005-2019 = EMPRATE, Employment rate of older workers, age group 55-64, average in 2005-2019 = EMPOLDWORKERS, Youth unemployment rate by sex, average in 20052019 = YOUTHUNEMP, Gender employment gap, average in 2005-2019= GENDEREMPGAP, Long-term unemployment rate by sex, average in 2005-2019 = LONGTERMEMP, Tertiary educational attainment, age group 30-34, average in 20052019= TERTEMP, Adult participation in learning by sex, average in 2000-2019 = ADULTLEARNING, Percentage of the population with at least upper secondary educational attainment, age group 25-64, average in 2005-2019= SECONDARYEDUCATION. 